\title{
Prins cyclisation of (-)-isopulegol with benzaldehyde over ZSM-5 based micro-mesoporous catalysts for production of pharmaceuticals
}

\author{
Ekaterina Kholkina a, Päivi Mäki-Arvela a, Chloe Lozachmeuer a, Roman Barakov b, \\ Nataliya Shcherban b, Dmitry Yu. Murzin a,* \\ a Johan Gadolin Process Chemistry Centre, Faculty of Science and Engineering, Åbo Akademi University, Turku 20500, Finland \\ ${ }^{\mathrm{b}}$ L.V. Pisarzhevsky Institute of Physical Chemistry, National Academy of Sciences of Ukraine, 31 pr. Nauky, Kiev 03028, Ukraine
}

\section{A R T I C L E I N F O}

\section{Article history:}

Received 7 December 2018

Accepted 17 January 2019

Published 5 November 2019

\section{Keywords:}

Micro-mesoporous material

Prins cyclisation

Tetrahydropyran

\begin{abstract}
A B S T R A C T
Several ZSM-5 derived micro-mesoporous catalysts were investigated in Prins cyclisation of (-)-isopulegol with benzaldehyde acting as a reactant and a solvent for production of heterocyclic oxygen containing $2 \mathrm{H}$-chromene derivatives including the tetrahydropyran structure and exhibiting biological activity. The investigated catalysts were characterized by nitrogen adsorption, ammonia temperature programmed desorption, adsorption-desorption of pyridine and 2,6-di-tert-butylpyridine with Fourier transform infrared spectroscopic control. For the Prins reaction performed at 70 ${ }^{\circ} \mathrm{C}$, the highest yield of the desired product, equal to $67 \%$ at complete conversion of $(-)$-isopulegol, was obtained over a micro-mesoporous catalyst containing an optimum amount of strong acid sites and mesopores, being 12 fold larger than the size of the desired product.
\end{abstract}

(C) 2019, Dalian Institute of Chemical Physics, Chinese Academy of Sciences. Published by Elsevier B.V. All rights reserved.

\section{Introduction}

Natural compounds are a valuable feedstock for synthesis of pharmaceuticals [1], already exhibiting desired functionalities. Important generic chemical structures in pharmaceuticals are oxygen-containing heterocyclic compounds, such as octahydrochromenes [2,3], which exhibit biological activity. Several octahydrochromenols have been reported to exhibit anti-influenza properties [4]. Furthermore, it has been recently established [2] that octahydrochromanes are active as cannabinoid receptors. In addition, thiophenyl-substituted octahydro-2-H-chromenol structures possess analgesic activity [5].

Octahydrochromanes can be prepared via the Prins cyclisation, for example, in a reaction between a monoterpenoid and an aldehyde in the presence of Lewis acid catalysts [6]. Several homogeneous catalysts, e.g. $\mathrm{BF}_{3}-\mathrm{OEt}_{2}$ [2], $\mathrm{HBF}_{4}-\mathrm{OEt}_{2}$ [7] and iodine [6] have been used for this type of reactions. For example (-)-isopulegol reacted with 2,6-dimethylbenzaldehyde in the presence of $\mathrm{BF}_{3}-\mathrm{OEt}_{2}$ in dichloromethane at $-40{ }^{\circ} \mathrm{C}$ forming biologically active octahydrochromanes [2]. Analogously a high yield of chromene, $80 \%$ was obtained in the reaction between p-anisaldehyde and (-)-isopulegol using $\mathrm{HBF}_{4}-\mathrm{OEt}_{2}$ as a catalyst at $0{ }^{\circ} \mathrm{C}$ in dichoromethane in $3 \mathrm{~h}$ [7]. Furthermore, iodine acts as a Lewis acid facilitating the reaction between (-)-isopulegol and 4-methoxymethylbenzaldehyde giving 81\% yield of the pyran in $24 \mathrm{~h}$ in dichloromethane at room temperature [6].

Heterogeneous solid acid catalysts have been recently tested as catalysts in Prins cyclisation, including as montmorillonite K10 [8,9], acid-modified halloysite nanotubes [5], zeolites [10] and a Ce-modified mesoporous MCM-41 composite [10]. It was also observed that octahydrochromane compound, with

\footnotetext{
* Corresponding author. E-mail: dmurzin@abo.fi DOI: S1872-2067(19)63305-X | http://www.sciencedirect.com/science/journal/18722067 | Chin. J. Catal., Vol. 40, No. 11, November 2019
} 


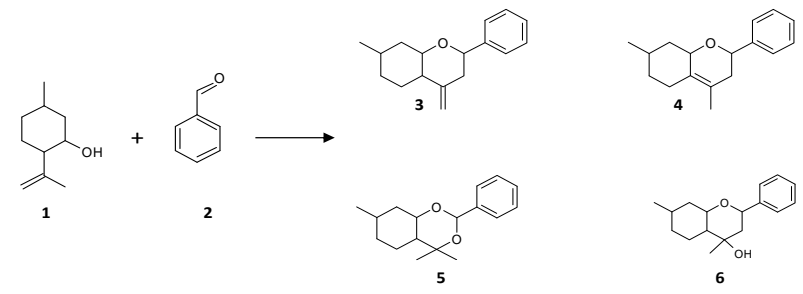

Fig. 1. Reaction scheme for Prins cyclisation of (-)-isopulegol (1) with benzaldehyde (2) for synthesis of product (6) with the tetrahydropyran structure. The other products are dehydration products (3) and (4) as well as dioxinol type product (5).

tetrahydropyran structure (compound 6 in Fig. 1), formed from $(-)$-isopulegol and benzaldehyde was further partially transformed to dioxinol type product $\mathbf{5}$ over Ce-modified mildly acidic MCM-41 composite material [11]. Dioxinol, being another valuable product from Prins cyclisation of (-)-isopulegol with benzaldehyde (Fig. 1), exhibits a benzodioxin structure possessing analgesic properties [12-15]. Several aldehydes, such as benzaldehyde, 4-methoxybenzaldehyde, 4-chlorobenzaldehyde, isovaleraldehyde and thiophene-2-carbaldehyde were investigated in Prins cyclisation of (-)-isopulegol using acid-modified halloysite nanotubes as catalysts [5]. High selectivity to $6(79 \%)$ was obtained in the reaction between (-)-isopulegol and benzaldehyde in cyclohexane at $20{ }^{\circ} \mathrm{C}$ [5]. Another interesting reaction is formation of a chromenol compound from (-)-isopulegol and vanillin. It was synthesized using kaolin and metakaolin as catalysts in toluene at $50{ }^{\circ} \mathrm{C}$ in $2 \mathrm{~h}$ giving maximally $90 \%$ selectivity at $63 \%$ conversion [9].

The aim of this work was to investigate ZSM- 5 based micro-mesoporous materials as catalysts in Prins cyclisation of (-)-isopulegol with benzaldehyde. These materials, successfully used in isomerization of $\alpha$-pinene oxide [16], have been prepared using several methods, such as dual-template, dual-functional template as well as steam-assisted methods. The micro-mesoporous catalysts facilitate better mass transfer compared to zeolites, especially when aiming to produce rather large molecules, such as chromenols (compound 6) via Prins cyclisation of (-)-isopulegol with benzaldehyde. Furthermore, the acidic properties of these catalysts can be tailored via selection of the preparation method and changing their Si/Al ratio. These catalysts have been fully characterized in our recent work using a range of physico-chemical methods [16].

\section{Experimental}

\subsection{Preparation and characterization of catalysts}

The catalysts were prepared using several preparation methods [16]. The catalysts denoted as 1MMAS and 2MMAS (MMAS - micro-mesoporous aluminosilicate) were prepared via the dual template method using ZSM-5 precursors in the reaction mixture containing molecular (tetrapropylammonium hydroxide, $40 \%$ aqueous solution, SACHEM, Inc.) and micellar (cetyltrimethylammonium chloride, 25\% aqueous solution, Aldrich) templates together with tetraethylorthosilicate (Al- drich, 98\%) and aluminium nitrate nonahydrate (Aldrich, 99\%) as silicon and aluminium sources respectively $(\mathrm{Si} / \mathrm{Al}=50$ in the reaction mixture). The reaction mixture was subjected to hydrothermal treatment at $100{ }^{\circ} \mathrm{C}$ for $48 \mathrm{~h}$ (sample 1MMAS) or $144 \mathrm{~h}$ (sample 2MMAS). The procedure for preparation of 1MMAS and 2MMAS is given in details in [17]. 3MMAS and 4MMAS were prepared by the steam-assisted method according to [18]. In their synthesis Si-SBA-15 was impregnated with $0.1 \mathrm{~mol} / \mathrm{L}$ TPAOH aqueous solution containing hydroxoaluminate ions. Aluminium isopropoxide (Aldrich, $\geq 98 \%$ ) was used as an aluminium source. The obtained dry gel was subjected to steam treatment at $120{ }^{\circ} \mathrm{C}$ for $24 \mathrm{~h}$ (3MMAS) or at $100{ }^{\circ} \mathrm{C}$ for $144 \mathrm{~h}$ (4MMAS) [18].

Preparation of 5MMAS-9MMAS $(\mathrm{Si} / \mathrm{Al}=50$ in the reaction mixture) done with dual-functional template (poly-quaternary ammonium surfactants) is described in detail in [16,19-21]. These samples were obtained at $130{ }^{\circ} \mathrm{C}$ (duration of hydrothermal treatment is $144 \mathrm{~h}$ ). As a comparison to MMAS catalysts, also AlSi-MCM-41, AlSi-SBA-15 and ZSM-5 (Si/Al = 50 in the initial mixtures of these materials) prepared in [22] were used as reference samples in this work as well.

The catalysts were characterized with X-ray diffraction (XRD), nitrogen adsorption, transmission electron microscopy (TEM), scanning electron microscopy (SEM), ammonia temperature programmed desorption (TPD), pyridine and 2,6-di-tert-butylpyridine adsorption-desorption with infrared (IR)-spectroscopic control. A detailed account of the characterization results is available in the previous work [16]. An average ZSM-5 crystallite size (average size of coherent scattering regions) was calculated by the Scherrer equation. The degree of crystallinity of the partially zeolitized samples was evaluated by a change in the ratio of the intensities of the characteristic reflexes at $2 \theta=23.0^{\circ}, 23.8^{\circ}, 24.2^{\circ}$ in comparison with ZSM-5 with the most intense reflexes in the XRD pattern, for which the degree of crystallinity was assigned as unity.

\subsection{Catalytic tests}

Prins cyclisation of $(-)$-isopulegol was performed with benzaldehyde using benzaldehyde both as a reactant and a solvent. In a typical experiment the initial concentration of (-)-isopulegol in $50 \mathrm{ml}$ of benzaldehyde was $0.013 \mathrm{~mol} / \mathrm{L}$. The catalyst $(100 \mathrm{mg})$, which was predried at $250{ }^{\circ} \mathrm{C}$ under argon flow for $30 \mathrm{~min}$, exhibited small particle size, below $90 \mu \mathrm{m}$ facilitating the reactions in the absence of internal mass transfer limitations. The stirring speed was $500 \mathrm{rpm}$ in order to suppress the external mass transfer limitations. The experiments were performed analogously to [12], where the absence of mass transfer limitations was elucidated by using different stirring speeds and catalyst masses. The samples were periodically withdrawn from the reactor and analysed by GC equipped with a HP-5 column $(30 \mathrm{~m}, 320 \mu \mathrm{m}, 0.5 \mu \mathrm{m})$. The retention times of the peaks were identified by GC-MS and compared with the corresponding data for the neat compounds. The initial reaction rates were calculated according to

$$
r_{0}=\left(c_{0}-c_{t}\right) \cdot V /\left(t \cdot m_{\text {cat }}\right)
$$

where $c_{0}, c_{t}$ are initial and actual concentrations of isopulegol 


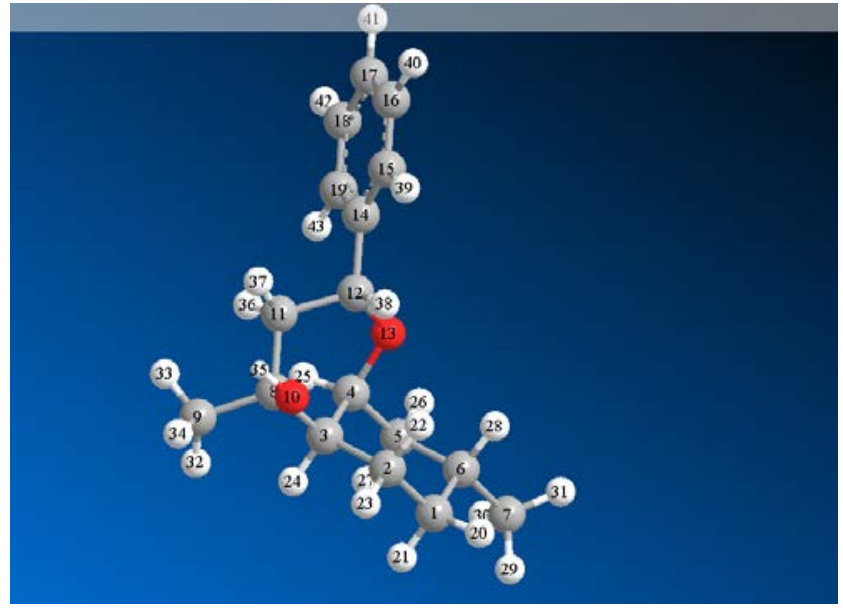

Fig. 2. MM2 minimization of compound (6) with the tetrahydropyran structure calculated using ChemDraw.

(mmol/L), $V$-reaction volume (L), $t$ is a reaction time $(1-15$ $\mathrm{min}$ ) and $m_{\text {cat }}$ is the catalyst mass (g).

\section{Results and discussion}

\subsection{Catalyst characterization results}

X-ray amorphous aluminosilicate (1MMAS) and partially zeolitized MMAS (sample 2MMAS, the degree of crystallinity $\alpha_{\text {cryst }}$ ca. 0.15 ) possessing mesostructure with a relatively low degree of spatial ordering (Fig. 3). According to FTIR the structure of the sample 1MMAS possesses (alumino)siloxane bond that may be able to assemble to crystalline zeolite framework [23]. The sample 1MMAS consists of amorphous spherical particles with the size of ca. $2 \mu \mathrm{m}$, similar to AlSi-MCM-41 (Fig. 4(a)). In sample 2MMAS in addition to amorphous particles, zeolite crystallites with the size of 0.3-0.4 $\mu \mathrm{m}$ (SEM image, Fig. 4(b)) are presented.

The aluminosilicates 3MMAS ( $\alpha_{\text {cryst }} \approx 0.10$, the crystallite size calculated from the Scherrer equation $\beta_{\text {cryst }}=23 \mathrm{~nm}$ ) and 4MMAS $\left(\alpha_{\text {cryst }} \approx 0.40, \beta_{\text {cryst }}=45 \mathrm{~nm}\right)$ possess a hexagonal
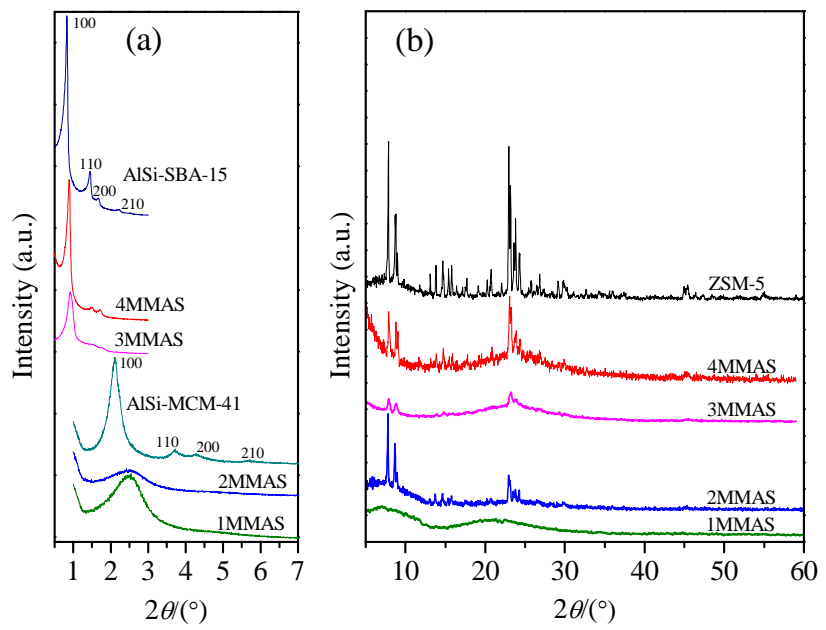

Fig. 3. Small-angle (a) and high-angle (b) XRD patterns of the samples 1MMAS-4MMAS, AlSi-MCM-41, AlSi-SBA-15 and ZSM-5.

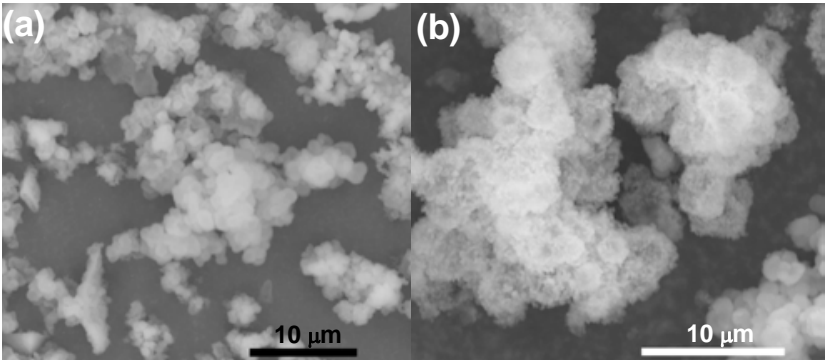

Fig. 4. SEM images of 1MMAS (a) and 2MMAS (b) samples.

mesostructure (Fig. 3). The rope-like particles (length of 1.5-2 $\mu \mathrm{m}$, Fig. 5(a)) with elements of SBA-15 mesostructure (the channel diameter is ca. $5 \mathrm{~nm}$, Fig. 5(b)) are observed in the TEM image of 3MMAS. A higher degree of spatial ordering of 4MMAS in comparison with 3 MMAS is associated with a decrease in destruction of the SBA-15 mesostructure under the steam treatment conditions at a lower temperature $\left(100^{\circ} \mathrm{C}\right)$.

The samples 5MMAS-7MMAS consisting of ZSM-5 zeolite nanoparticles agglomerates with the size of 27-36 nm (Figs. 6 and $7(a)$ and (b)) were formed in the reaction mixture with the dual-functional template $\mathrm{C}_{8-6-8} \mathrm{Br}_{2}$ in combination with additives of micellar cetyltrimethylammonium bromide and molecular TPAOH templates [21]. The use of a dual-functional template $\mathrm{C}_{16-6-6 \mathrm{Br}_{2}}$ and TPAOH allows to obtain 8MMAS and 9MMAS materials (Fig. 6) consisting of randomly oriented flake-like particles, which are the packs of ZSM-5 (a thickness of

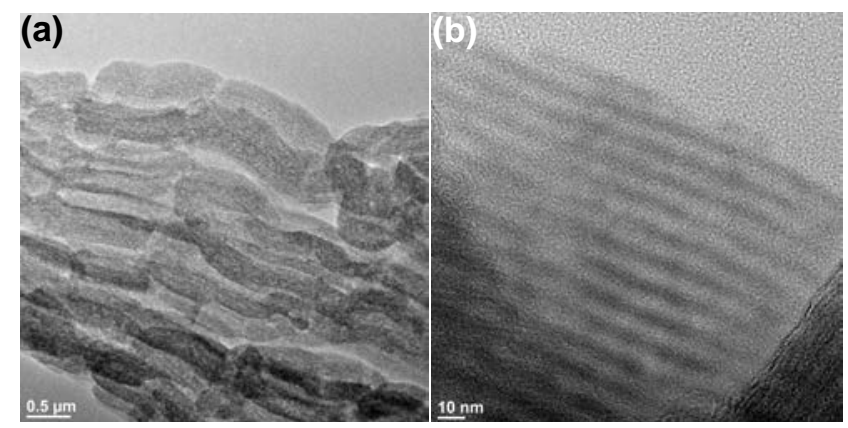

Fig. 5. TEM images of 3MMAS.

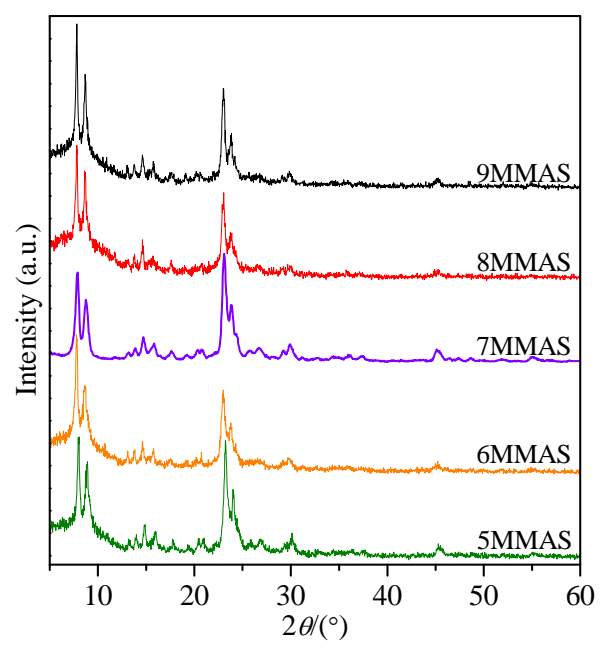

Fig. 6. XRD patterns of 5MMAS-9MMAS. 

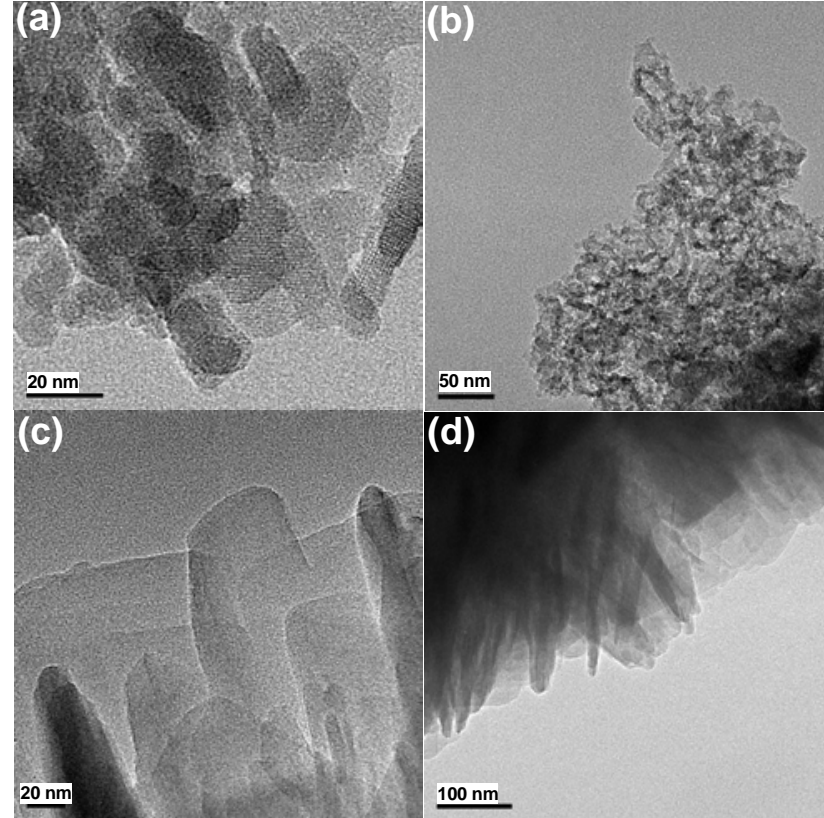

Fig. 7. TEM images of 5MMAS (a), 6MMAS (b), 8MMAS (c) and 9MMAS (d) samples.

a layer is ca. $2 \mathrm{~nm}$ in a direction of the crystallographic axis $b$ ) with the overall thickness of 10-40 nm (Fig. 7(c) and (d)) [21].

The main catalyst properties, such as the specific surface area, mesopore size, Si/Al ratio, ammonia TPD and accessibility index, defined as the ratio between the measured Brønsted acid site concentration with 2,6-di-tert-butylpyridine compared to pyridine, are shown in Table 1 . The results illustrate that the highest specific mesopore surface area was exhibited by 1MMAS followed by 2MMAS, whereas the specific mesopore surface areas of all other catalysts are much smaller. ZSM-5 is a medium pore size zeolite (micropore diameter is $0.55 \mathrm{~nm}$ ) with a very low specific mesopore surface area. As expected mesoporous AlSi-MCM-41 has 2.2 fold higher specific mesopore surface area than AlSi-SBA-15.

The mesopore diameter together with the catalyst acidity are the two main parameters determining the catalytic activity in Prins cyclisation of $(-)$-isopulegol with benzaldehyde (Table 1), since the product 6 has a distance between H29 and H33 in $y$ - $x$-direction of 0.7 and $0.9 \mathrm{~nm}$ in y direction between $\mathrm{H} 29$ and H41 determined by ChemDraw (Fig. 2). The smallest mesopores found in 1MMAS being of about $2.3 \mathrm{~nm}$ in size, do not limit diffusion of the product out from this catalyst. The largest mesopores are found in 7MMAS followed by 5MMAS. In addition, Al-SBA-15 has also large mesopores.

Acidity, and especially concentration of strong acid sites along with the accessibility index, are crucial for the Prins reaction. According to ammonia TPD data, the X-ray amorphous material 1MMAS (with $\mathrm{Si} / \mathrm{Al}$ ratio of 33) containing ZSM-5 precursors is characterized by the presence of acid sites of medium strength (concentration is $154 \mu \mathrm{mol} / \mathrm{g}$, shoulder with $\mathrm{NH}_{3}$ desorption maximum at $320^{\circ} \mathrm{C}$, Table 1 ). The aluminosilicate 2MMAS ( $\mathrm{Si} / \mathrm{Al}=27$ ), with a degree of zeolitization of 0.15 , has acid sites of medium strength (ammonia desorption maximum at $350{ }^{\circ} \mathrm{C}$, Table 1$)$, as well as strong acid sites $\left(\mathrm{NH}_{3}\right.$
Table 1

Catalyst characterization results.

\begin{tabular}{|c|c|c|c|c|c|c|}
\hline Catalyst & $\begin{array}{l}D_{\text {meso }} \\
(\mathrm{nm})\end{array}$ & $\begin{array}{c}S_{\text {meso }} \\
\left(\mathrm{m}^{2} / \mathrm{g}_{\text {cat }}\right)\end{array}$ & $\mathrm{Si} / \mathrm{Al}$ & $\begin{array}{c}T \max \\
\left(\mathrm{NH}_{3}\right)\left({ }^{\circ} \mathrm{C}\right)\end{array}$ & $\begin{array}{c}\mathrm{C} \\
(\mu \mathrm{mol} / \mathrm{g})\end{array}$ & $\begin{array}{l}\text { Accessibility } \\
\text { index }\end{array}$ \\
\hline \multirow[t]{2}{*}{ 1MMAS } & $2.3 \pm 0.4$ & 1240 & 33 & 210 & 60 & 0.81 \\
\hline & & & & 320 & 154 & \\
\hline \multirow[t]{3}{*}{ 2MMAS } & $2.4 \pm 0.4$ & 815 & 27 & 200 & 102 & 0.80 \\
\hline & & & & 350 & 81 & \\
\hline & & & & 450 & 17 & \\
\hline \multirow[t]{2}{*}{ 3MMAS } & $6.3 \pm 0.9$ & 280 & 59 & 185 & 78 & 0.72 \\
\hline & & & & 325 & 117 & \\
\hline \multirow[t]{2}{*}{ 4MMAS } & $7.0 \pm 0.9$ & 275 & 53 & 200 & 54 & 0.74 \\
\hline & $13.0 \pm 1.1$ & & & 330 & 115 & \\
\hline \multirow[t]{2}{*}{ 5MMAS } & $11.0 \pm 2.0$ & 175 & 34 & 210 & 200 & 0.12 \\
\hline & & & & 440 & 196 & \\
\hline \multirow[t]{2}{*}{ 6MMAS } & $5.6 \pm 0.6$ & 250 & 36 & 195 & 145 & 0.34 \\
\hline & & & & 425 & 173 & \\
\hline \multirow[t]{2}{*}{ 7MMAS } & $25.0 \pm 7.5$ & 75 & 42 & 200 & 63 & 0.06 \\
\hline & & & & 405 & 122 & \\
\hline \multirow[t]{2}{*}{ 8MMAS } & $2.5 \pm 1.0$ & 240 & 41 & 215 & 185 & 0.15 \\
\hline & & & & 440 & 159 & \\
\hline \multirow[t]{2}{*}{ 9MMAS } & $2.7 \pm 0.6$ & 230 & 42 & 200 & 213 & 0.15 \\
\hline & & & & 440 & 217 & \\
\hline \multirow[t]{2}{*}{ ZSM-5 } & - & 5 (exter- & 30 & 210 & 170 & 0.03 \\
\hline & & $\begin{array}{c}\text { nal sur- } \\
\text { face area) }\end{array}$ & & 440 & 136 & \\
\hline \multirow[t]{2}{*}{ AlSi-MCM-41 } & $2.9 \pm 0.2$ & 890 & 37 & 220 & 34 & 0.97 \\
\hline & & & & 320 & 26 & \\
\hline \multirow[t]{2}{*}{ AlSi-SBA-15 } & $9.2 \pm 0.5$ & 400 & 23 & 215 & 34 & 1.0 \\
\hline & & & & 300 & 61 & \\
\hline
\end{tabular}

maximum desorption temperature at $450{ }^{\circ} \mathrm{C}$ ). The partially zeolitized aluminosilicates 3MMAS, 4MMAS ( $\mathrm{Si} / \mathrm{Al}=53-59)$ obtained by crystallization of SBA-15 contain predominantly medium strength acid sites (concentration is 115-117 $\mu \mathrm{mol} / \mathrm{g}$, $\mathrm{NH}_{3}$ maximum desorption at $325-330{ }^{\circ} \mathrm{C}$ ). According to pyridine adsorption-desorption with IR-spectroscopic control, the ratio of concentrations of Brønsted (42-74 $\mu \mathrm{mol} / \mathrm{g}$ ) and Lewis (64-149 $\mu \mathrm{mol} / \mathrm{g}$ ) acid sites in 1MMAS-4MMAS is 0.5-0.7 (pyridine is almost completely desorbed from Brønsted sites at $350-400{ }^{\circ} \mathrm{C}$ ). The most of the Brønsted acid sites (concentration is $31-61 \mu \mathrm{mol} / \mathrm{g}$ ) in these aluminosilicates are accessible for bulk molecules (the accessibility index is 0.72-0.82). 5MMAS-9MMAS materials of the zeolite type $(\mathrm{Si} / \mathrm{Al}$ ratio $=$ 34-42) contain strong acid sites (according to ammonia TPD, Table 1), similar to ZSM-5 zeolite ( $\mathrm{Si} / \mathrm{Al}=30)$. These samples are characterized by stronger Brønsted acid sites and their higher concentration (74-148 $\mu \mathrm{mol} / \mathrm{g}$, pyridine is completely desorbed from these sites at $450{ }^{\circ} \mathrm{C}$ ), as well as a higher ratio of Brønsted and Lewis acid sites concentration (2.6-5.0, Lewis acid sites concentration is $20-52 \mu \mathrm{mol} / \mathrm{g}$ ), in comparison with partially zeolitized materials. However, these aluminosilicates are characterized by a low accessibility index of Brønsted acid sites for bulk molecules (up to 0.34, the concentration of Brønsted acid sites by ad(de)sorption of 2,6-di-tert-butylpyridine is $7-24 \mu \mathrm{mol} / \mathrm{g}$ ).

The concentration of strong acid sites by ammonia TPD decreases as follows: 9MMAS > 5MMAS > 6MMAS > 8MMAS > 7MMAS. Furthermore, it should be noted, that although 6MMAS contains strong acid sites, the maximum ammonia desorption peak for this catalyst is at $425^{\circ} \mathrm{C}$, whereas the corresponding 
value of $440{ }^{\circ} \mathrm{C}$ for 5 MMAS indicate a higher acid strength in 5MMAS than in 6MMAS (Table 1 ).

The accessibility index decreases in the following order: Al-SBA-15 > Al-MCM-41 > 1MMAS > 2MMAS > 4MMAS > 3MMAS $>6$ MMAS $>$ 8MMAS $=$ 9MMAS $>$ MMMAS $>$ 7MMAS $>$ ZSM-5. It should be noted that the kinetic diameter of 2,6-di-tert-butylpyridine is $0.8 \mathrm{~nm}$ [24] being in the same range as the dimensions for the product $\mathbf{6}$ and thus a comparison of the accessibility index and a possibility for compound $\mathbf{6}$ to diffuse out from the catalyst is justified.

\subsection{Catalytic results}

The highest initial rates in Prins cyclisation of (-)-isopulegol with benzaldehyde were obtained with 5MMAS, which exhibits a quite high amount of strong acid sites (Table 2). The second highest initial rate was determined for 1MMAS which has the strongest acid sites for which ammonia was desorbing at 320 ${ }^{\circ} \mathrm{C}$. This catalyst has, however, an accessibility index higher than 5MMAS. A mildly acidic mesoporous Al-MCM-41 exhibited the third highest initial rate. Analogously to 1MMAS this catalyst exhibited a high accessibility index and only mild acidity. These results indicate that one of the factors determining the initial rate is high accessibility. It is also important to note that 9MMAS possessing a very large amount of strong acid sites exhibits the initial rate which is only $32 \%$ of the initial rate for 5MMAS showing that a too high amount of strong acid sites is not favourable. These results were correlated with the initial rates obtained over different zeolites, mesoporous materials and metal modified zeolites by Stekrova et al. [11], who concluded that too high amounts of strong acid sites, especially in $\mathrm{Au}$-Beta-25, give lower initial rates than the parent zeolites and mildly acidic Ce-MCM-41. Noteworthy is that the initial rate for 4MMAS was very low, however, this material was very active already during heating of the reaction mixture. The following catalysts 2MMAS, 3MMAS and 4MMAS exhibited low initial rates, being, however, active already during the heating period. These catalysts did not convert completely (-)-isopulegol, which is related to their mild acidity. In comparison with 1MMAS, which contains much more acid sites desorbing ammonia at $320^{\circ} \mathrm{C}$ than 3 MMAS and 4MMAS, it can be stated the

Table 2

Catalytic results.

\begin{tabular}{lccc}
\hline Catalyst & $\begin{array}{c}\text { Initial reaction rate } \\
\left(\mathrm{mmol} / \mathrm{min}_{\mathrm{cat}}\right)\end{array}$ & $\begin{array}{c}\text { Conversion after } \\
180 \mathrm{~min}(\%)\end{array}$ & $\begin{array}{c}\text { GCLPA } \\
(\%)\end{array}$ \\
\hline 1MMAS & 0.09 & 100 & 86 \\
2MMAS & Very low & 100 & 79 \\
3MMAS & 0.03 & 54 & 79 \\
4MMAS & Very low & 80 & 74 \\
5MMAS & 0.22 & 100 & 100 \\
6MMAS & 0.033 & 75 & 38 \\
7MMAS & 0.03 & 28 & 94 \\
8MMAS & 0.1 & 66 & 100 \\
9MMAS & 0.07 & 80 & 93 \\
ZSM-5 & Very low & 19 & 59 \\
AlSi-MCM-41 & 0.19 & 100 & 58 \\
AlSi-SBA-15 & 0.04 & 33 & 100 \\
\hline aCLPA-the sum of the masses of reactant and products visible in GC \\
analysis.
\end{tabular}

low initial rate calculated for the reaction time between 1 and 30 min stems from too low acidity, analogously to Al-SBA-15. ZSM-5 zeolite is not active in this reaction due to the spatial limitations of the microporous structure for the formation of bulk products.

A comparison of conversion as a function of time obtained over different catalysts is depicted in Fig. 8. The rates after already 15 min decrease substantially for Al-SBA-15 and 7MMAS. The former catalyst has too low acidity to catalyse (-)-isopulegol reaction with benzaldehyde, whereas the latter one although exhibiting high acidity, has the lowest accessibility index among all the studied catalysts.

A complete conversion of (-)-isopulegol was obtained with 1MMAS, 2MMAS, 5MMAS and Al-MCM-41 (Fig. 8). Among these catalysts 1 MMAS and Al-MCM-41 exhibit very mild acidity but a high accessibility index, whereas both 2MMAS and 5MMAS contain relatively high amounts of strong acid sites. Furthermore, it is noteworthy that although the accessibility index of 5MMAS is rather low, 0.12 , it is a very active catalyst (Table 1 ). Its mesopores are rather large (Table 1) and it should be concluded that its acidity is adequate for catalysing this reaction. When comparing the current results with those reported previously in [12], it can be seen that a complete conversion was obtained with Ce-MCM-41, exhibiting mild acidity, but also some strong acid sites analogously to Al-MCM-41 in the current work. On the other hand, a low conversion level of $21 \%$ obtained in the current work over Al-SBA-15 can be explained by the absence of strong acid sites. Opposite to Al-SBA-15, a low conversion for 7MMAS is explained by its low accessibility index. As discussed above, 3MMAS and 4MMAS did not give complete conversion of $(-)$-isopulegol because of too low acidity. 8MMAS and 9MMAS exhibit smaller mesopores than Al-Si-MCM-41, which can explain their lower conversion levels compared to Al-MCM-41. On the other hand, ZSM-5, being strongly acidic is not able to convert (-)-isopulegol via addition reaction due to its small pore size [25]. The same is valid with 7MMAS which has a low accessibility index.

The liquid phase mass balance closure was also investigated by calculating the sum of concentrations of all compounds visible in the GC analysis. The results showed that only 5MMAS, 8MMAS and Al-SBA-15 were giving a complete mass balance closure (Table 2). The catalysts not giving the complete mass

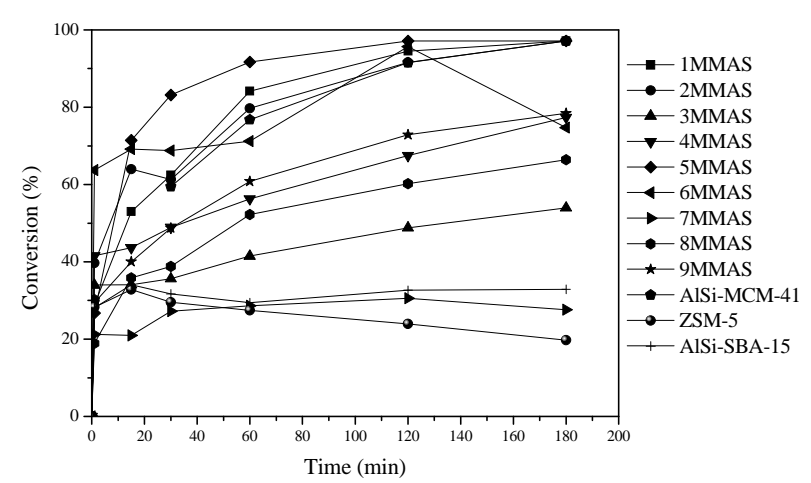

Fig. 8. Conversion of $(-)$-isopulegol as a function of time over different catalysts in Prins cyclisation of (-)-isopulegol with benzaldehyde at 70 ${ }^{\circ} \mathrm{C}$. 


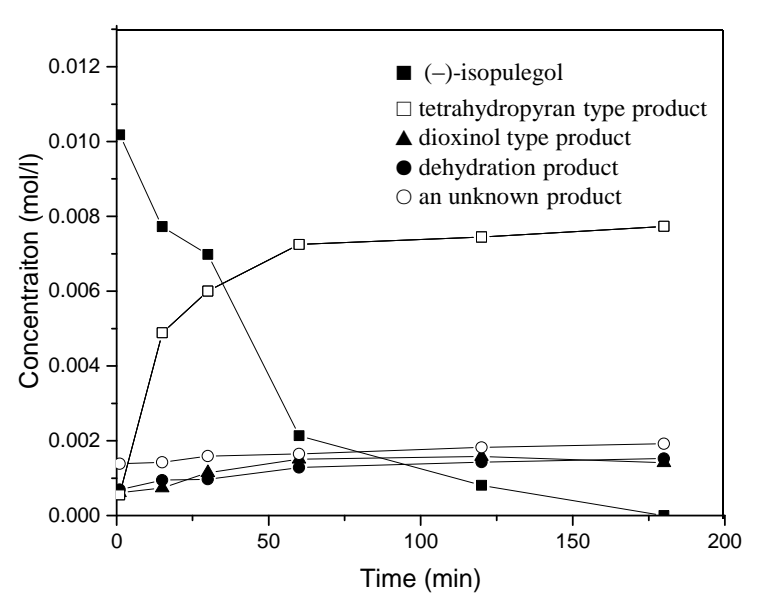

Fig. 9. Kinetics in Prins cyclisation of $(-)$-isopulegol with benzaldehyde over $5 \mathrm{MMAS}$ catalyst at $70^{\circ} \mathrm{C}$ in benzaldehyde as a solvent.

balance closure were either containing small pores, such as ZSM-5, 7MMAS, or their ability was not high enough, e.g. 1MMAS, 2MMAS, 3MMAS, 6MMAS, 7MMAS and AlSi-MCM-41.

The best catalyst giving the highest yield of $6,67 \%$, was 5MMAS. This catalyst contained a quite high concentration of strong acid sites (Table 1) exhibiting a rather small accessibility index of 0.12 . It should, however, be noted that the mesopores in this catalyst were $11 \mathrm{~nm}$, which is 12 times larger than the size of product 6 indicating that a large pore size is required for formation of this product. In addition, 5MMAS is characterised by a higher mesopore volume $\left(0.51 \mathrm{~cm}^{3} / \mathrm{g}\right)$, in comparison with 6MMAS-9MMAS $\left(0.30-0.34 \mathrm{~cm}^{3} / \mathrm{g}\right)$, which also contain strong acid sites according to TPD of $\mathrm{NH}_{3}$. Mesopore volume of 1MMAS-4MMAS is $0.50-0.67 \mathrm{~cm}^{3} / \mathrm{g}$. By comparing the yield of product 6 in the current case with the results obtained over H-Beta zeolites [11], it can be stated that zeolites give selectivities in the range of $66 \%-74 \%$, whereas the highest yield of 6 was obtained in [11] over a mildly acidic Ce-MCM-41 catalyst. This latter catalyst also exhibited a small amount of strong acid sites. It was also reported in [5] that mild Brønsted acid sites were beneficial for production of chromenol type structures. For the best catalyst in this work, 5MMAS, which contains also

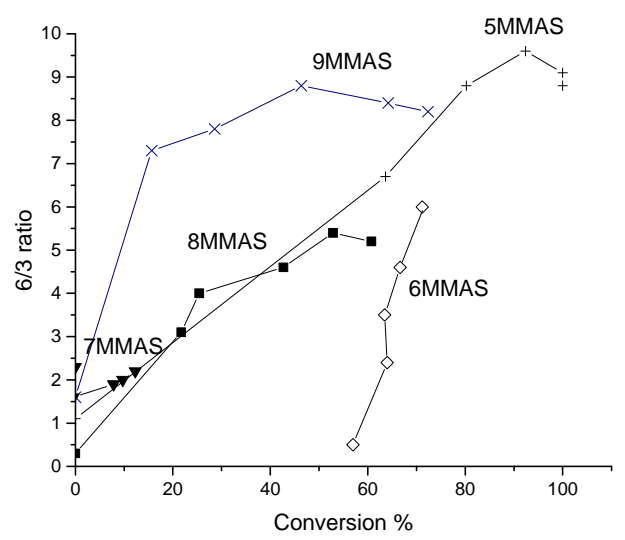

(a)

Fig. (b). an optimum amount of strong acid sites, most probably the most important factor is its rather low accessibility index, limiting involvement of a part of its strong acid sites in catalysis.

The product distribution obtained over different catalysts can be compared by plotting the molar ratio of $6 / 3$ as a function of conversion (Fig. 10). The results show that this ratio is increasing with increasing conversion up to a maximum, after which it decreases. This result is interpreted to occur due to catalyst deactivation in the presence of an aldehyde, benzaldehyde, which can be decarbonylated suppressing the dehydration reaction. After reaching the maximum, the increase of the amount of $\mathbf{6}$ is retarded due to formation of an unknown product, especially over 1MMAS, 2MMAS, AISi-MCM-41 and 8MMAS. The first three catalysts are mildly acidic, whereas 8MMAS contains relatively small mesopores and strong acidity. The highest ratio between $\mathbf{6 / 3}$, being 9.5 , is obtained with 5MMAS at $86 \%$ conversion (Fig. 10(a)). It is also interesting that for 8MMAS the amount of $\mathbf{6}$ is increasing very much in comparison to the amount of $\mathbf{3}$. This catalyst exhibits an adequately high accessibility index and a moderate amount of strong acid sites. The 6/3 molar ratio is very low for 2MMAS and Al-SBA- 15 . The former catalyst contains a very small amount of strong acid sites while the latter has no strong acid sites, which clearly shows that a sufficient amount of strong acid sites is required for production of 3 . The above mentioned results can be summarized when the $\mathbf{6 / 3}$ molar ratio is plotted as a function of accessibility index (Fig. 11). This figure clearly illustrates that when the ratio $6 / 3$ is plotted at $60 \%$ conversion, the best catalysts are 5MMAS, 9MMAS and AISi-MCM-41. The mass balance closure was not completed with 9MMAS and thus the yield of 6 was only $86 \%$ of the yield of 6 obtained over 5MMAS. Furthermore, AlSi-MCM-41, although giving complete conversion, the yield of product 6 was $88 \%$ of the one obtained over 5MMAS due to formation of an unknown product. The ratio 6/3 after 180 min was also plotted as function of conversion (Fig. 11(b)) showing clearly that the highest molar ratio of $\mathbf{6 / 3}$ was obtained with 5MMAS after $3 \mathrm{~h}$ implying that either too low accessibility or too low acidity are not beneficial for synthesis of compound 6. Furthermore, although 6MMAS exhibited also, analogously to 5MMAS, strong acid sites, it gave a very low

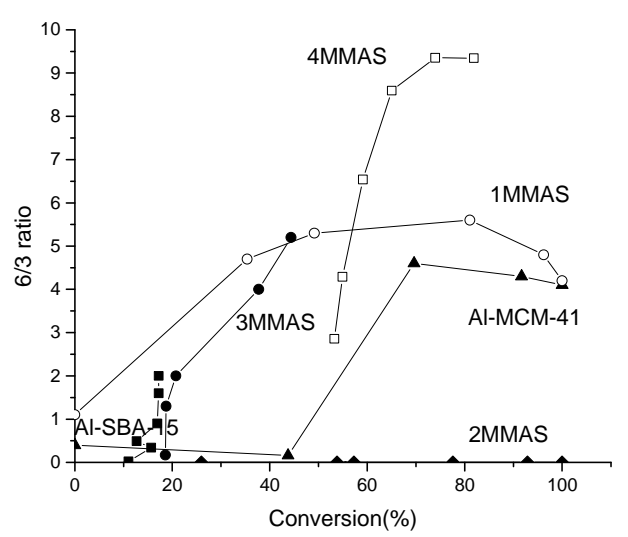

(b) 


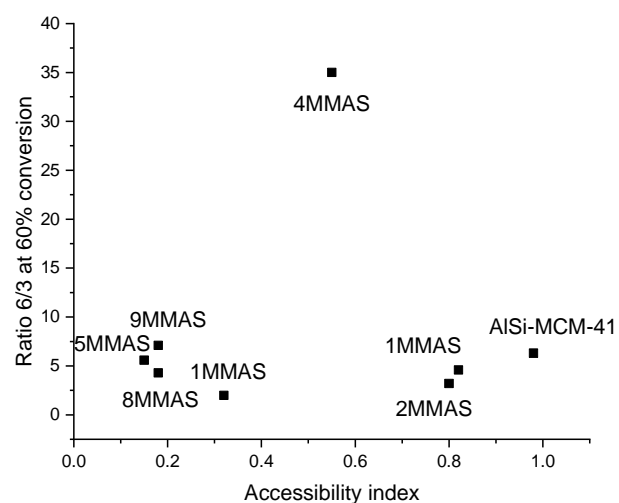

(a)

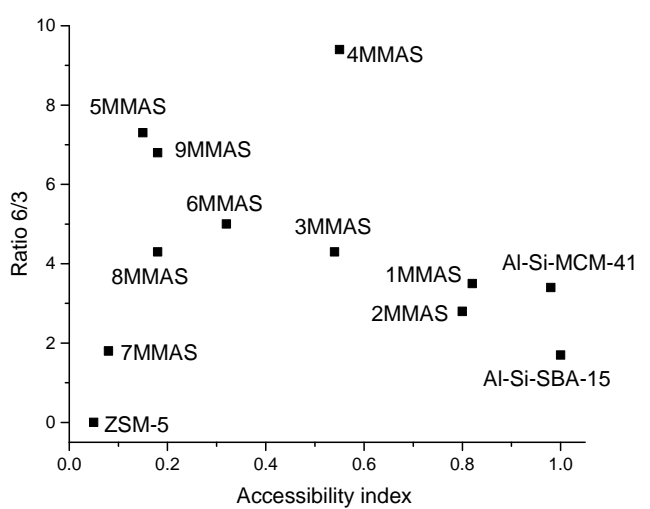

(b) mass balance closure and much lower ratio of $6 / 3$ than 5MMAS. The difference in these catalysts was the 2.8 fold higher accessibility index for 6MMAS compared to 5MMAS and thus a large amount of strong acid sites is available for the reaction over 6MMAS. Although 6/3 ratio was also very high for 4MMAS, the yield of 6 was only 38\%, whereas it was $54 \%$ over 5MMAS. The mass balance closure was not complete for 4MMAS opposite to 5MMAS. Furthermore, 4MMAS possessed mild Brønsted acid sites, whereas 5MMAS contains also strong acid sites. It has been observed previously [5] that formation of dehydration product increases with increasing catalyst acidity, in line with this work.

In the current work typically rather low amounts of dioxinol, 5, were formed analogously to [11] over H-Beta zeolites in the reaction between benzaldehyde and (-)-isopulegol. The ratio between $\mathbf{6 / 5}$ was increasing with increasing conversion over 1MMAS and 5MMAS and 9MMAS out of which the first one is mildly acidic, whereas the two latter ones, although being highly acidic, exhibit small accessibility index. It is also noteworthy that the dioxinol type compound was the main product formed in the reaction between benzaldehyde and verbenol oxide over H-Beta-150 [13] indicating that the reactant structure has a large effect on the product distribution. The amount of compound $\mathbf{5}$ is relatively high being $20 \%$ of the amount of $\mathbf{6}$ over AISi-MCM-41, which exhibits mild acidity, whereas it is slightly lower over 5MMAS containing more strong acid sites. This result is in accordance with [11] where similar observations were reported for $\beta$-zeolites. Dioxinol, compound $\mathbf{5}$, reacts further to unknown products at high conversion levels over 1MMAS, 5MMAS, 9MMAS and Al-MCM-41.

\section{Conclusions}

Prins cyclisation between (-)-isopulegol and benzaldehyde was investigated over micro-mesoporous ZSM-5 based catalysts using benzaldehyde as a solvent at $70{ }^{\circ} \mathrm{C}$. The highest yield of the desired product, tetrahydropyran, finding applications in pharmaceuticals, was obtained over 5MMAS exhibiting a large amount of strong acid sites, but a low accessibility index, i.e. the ratio between Brønsted acid sites determined by 2,6-di-tertbutylpyridine and pyridine. Thus the most important parame- ter for production of tetrahydropyran was the adequate amount of strong and medium strength acid sites. Formation of a dehydration product was enhanced with too acidic catalysts, such as 6MMAS which exhibited a high accessibility index. The parent ZSM-5 was not active in this reaction due to its small pore size. In comparison with micro-mesoporous ZSM- 5 based catalysts, the performance of AlSi-MCM-41 and Al-Si-SBA-15 were also studied. The former catalyst was better in producing tetrahydropyran than the latter one due to its mild acidity.

\section{References}

[1] O. S. Patrusheva, K. P. Volcho, N. F. Salakhutdinov, Russ. Chem. Rev., 2018, 87, 771-796.

[2] S. Slater, P. B. Lasonkar, S. Haider, M. J. Alqahtani, A. G. Chittiboyina, I. A. Khan, Tetrahedron Lett., 2018, 59, 807-810.

[3] I. V. Ilina, K. P. Volcho, Z. V. Viktorovich, N. F. Salakhutdinov, RU 2664728 C1, 2006.

[4] I. V. Ilyina, V. V. Zarubaev, I. N. Lavrentina, A. A. Shtro, I. L. Esaulkova, D. V. Korchagina, S. S. Borisevich, K. P. Volcho, N. F. Salakhutdinov, Bioorg. Med. Chem. Lett., 2018, 28, 2061-2067.

[5] A. Y. Sidorenko, A. V. Kravtsova, J. Wärnå, A. Aho, I. Heinmaa, I.V. Il'ima, Q. V. Ardashov, K. P. Volcho, N. F. Salakhutdinov, D. Y. Murzin, V. E. Agabekov, Mol. Catal., 2018, 453, 139-148.

[6] K. R. Kishore Kumar Reddy, I. M. L. Rosa, A. C. Doriguetto, E. L. Bastos, L. F. Siulva, Molecules, 2013, 18, 11100-11130.

[7] B. Sarmah, G. Baihya, R. K. Baruah, Eur. J. Org. Chem., 2014, 2014, 7561-7565.

[8] K. R. Kishore, K. Reddy, L. F. Silva Jr, J. Braz. Chem. Soc., 2013, 24, 9, 1414-1419.

[9] G. Baishya, B. Sarmah, N. Hazarika, Synlett, 2013, 24, 1137-1141.

[10] M. N. Timofeeva, V. N. Pancheno, K. P. Volcho, S. V. Zakusin, V. V. Krupskaya, A. Gil, O. S. Mikhalchenko, J. Mol Catal. A, 2016, 414, 160-166.

[11] M. Stekrova, P. Mäki-Arvela, N. Kumar, E. Behvaresh, A. Aho, Q. Balme, K. P. Volcho, N. F. Salakhutdinov, D. Y. Murzin, J. Mol. Catal. A, 2015, 410, 260-270.

[12] M. Stekrova, P. Mäki-Arvela, E. Leino, K. M. Valkaj, K. Eränen, A. Aho, A. Smeds, N. Kumar, K. P. Volcho, N. F. Salakhutdinov, D. Y. Murzin, Catal. Today, 2017, 279, 56-62.

[13] A. Torozova, P. Mäki-Arvela, A. Aho, N. Kumar, A. Smeds, M. Peurla, R. Sjöholm, I. Heinmaa, D. V. Korchagina, K. P. Volcho, N. F. Salakhutdinov, D. Y. Murzin, J. Mol. Catal. A, 2015, 397, 48-55. 


\title{
Graphical Abstract
}

Chin. J. Catal., 2019, 40: 1713-1720 doi: S1872-2067(19)63305-X

Prins cyclisation of (-)-isopulegol with benzaldehyde over ZSM-5 based micro-mesoporous catalysts for production of pharmaceuticals

Ekaterina Kholkina, Päivi Mäki-Arvela, Chloe Lozachmeuer, Roman Barakov, Nataliya Shcherban, Dmitry Yu. Murzin Åbo Akademi University, Finland; National Academy of Sciences of Ukraine, Ukraine

Strongly acidic MMAS catalysts were beneficial in Prins cyclisation for production of biologically active $2 \mathrm{H}$-chromene derivatives.

[14] S. Yu. Kurbakova, I. V. Il'ina, A. Pavlona, D. Korchagina, O. Yarovaya, T. Tolstikova, K. P. Volcho, N. F. Salakhutdinov, Med. Chem. Res., 2014, 23, 1709-1717.

[15] I. V. Il'ina, D. V. Korshagina, K.P. Volcho, N. F. Salakhutdinov, G. A. Tolstikov, Russ. J. Org. Chem., 2010, 46, 1002-1005.

[16] N. D. Shcherban, R. Y. Barakov, P. Mäki-Arvela, S. A. Sergiienko, I. Bezverkhyy, K. Eränen, D. Y. Murzin, Appl. Catal. A, 2018, 60, 236-247.

[17] R. Barakov, N. Shcherban, P. Yaremov, S. Gryn, V. Solomakha, I. Bezverkhyy, N. Kasian, V. Ilyin, J. Mater. Sci., 2016, 51, 4002-4020.

[18] R. Y. Barakov, N. D. Shcherban, P. S. Yaremov, S. M. Filomenko, V. V. Tsyrina, V. G. Ilyin, Theor. Exp. Chem., 2017, 53, 60-68.

[19] K. Na, M. Choi, W. Park, Y. Sakamoto, O. Terasaki, R. Ryoo, J. Am.

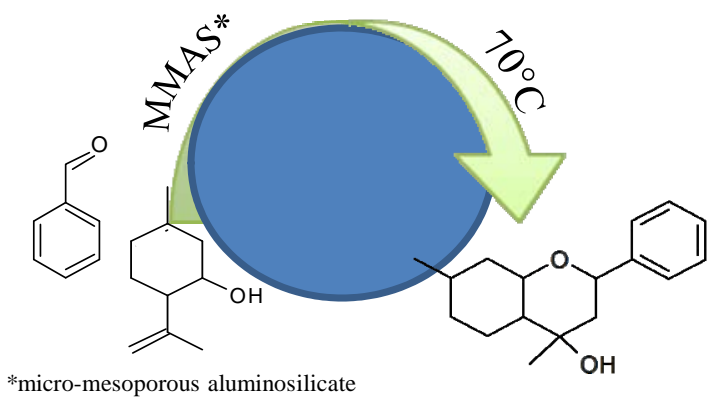

*micro-mesoporous aluminosilicate

Chem. Soc., 2010, 132, 4169-4177.

[20] K. Kim, R. Ryoo, H. D. Jang, M. Choi, J. Catal., 2012, 288, 115-123.

[21] R. Barakov, N. Shcherban, P. Yaremov, I. Bezverkhyy, A. Baranchikov, V. Trachevskii, V. Tsyrina, V. Ilyin, Microporous Mesoporous Mater., 2017, 237, 90-107.

[22] S. Wu, Y. Han, Y. C. Zou, J. W. Song, L. Zhaoi, Y. Di, S. Z. Liu, F. S. Xiao, Chem. Mater., 2004, 16, 486-492.

[23] C. E. A. Kirschhock, R. Ravishankar, F. Verspeurt, P. J. Grobet, P. A. Jacobs, J. A. Martens, J. Phys. Chem. B, 1999, 103, 4965-4971.

[24] K. Góra-Marek, K. Tarach, M. Choi, J. Phys. Chem. C, 2014, 118, 12266-12274.

[25] D. H. Olson, G. T. Kokotallo, S. L. Lawton, J. Phys. Chem., 1991, 85, 2238-2243.

\section{基于ZSM-5的微孔-中孔催化剂上(-)-异蒲勒醇与苯甲醛Prins环化反应合成药物}

\author{
Ekaterina Kholkina ${ }^{a}$, Päivi Mäki-Arvela ${ }^{\text {a }}$, Chloe Lozachmeuer ${ }^{\text {a }}$, Roman Barakov ${ }^{\text {b }}$, Nataliya \\ Shcherban ${ }^{\text {b }}$, Dmitry Yu. Murzin ${ }^{\mathrm{a}, *}$ \\ a博阿卡德米大学科学与工程系, 约翰·盖多林过程化学中心, 土尔库20500, 芬兰 \\ b乌克兰国家科学院L.V. Pisarzhevsky物理化学研究所, 基辅03028, 乌克兰
}

\begin{abstract}
摘要: 将数个ZSM-5基微孔-中孔催化剂用于(-)-异蒲勒醇与用作反应物和溶剂的苯甲醛进行Prins环化反应, 合成杂环含氧 $2 \mathrm{H}$-色烯衍生物, 其包含四氢吡喃结构并表现出生物活性. 采用 $\mathrm{N}_{2}$ 吸附, 氨-程序升温还原, 吡啶和2,6-二-叔丁基吡啶吸附脱附的红外光谱表征了所考察的催化剂. 当在含适量强酸位和 12 倍所需产物尺寸的中孔的催化剂上, 于 $70{ }^{\circ} \mathrm{C}$ 下进行Prins 反应, (-)-异蒲勒醇完全转化时所需产物产率最高达 $67 \%$.
\end{abstract}

关键词: 微孔-中孔材料; Prins成环反应; 四氢吡喃

收稿日期: 2018-12-07. 接受日期: 2019-01-17. 出版日期: 2019-11-05.

*通讯联系人. 电子信箱: dmurzin@abo.fi

本文的电子版全文由Elsevier出版社在ScienceDirect上出版(http://www.sciencedirect.com/science/journal/18722067). 